\title{
Reduced Cytosolic Calcium as an Early Decisive Cellular State in Parkinson's Disease and Synucleinopathies
}

\author{
Cristine Betzer ${ }^{1,2}$ and Poul Henning Jensen ${ }^{1,2 *}$ \\ ${ }^{1}$ DANDRITE - Danish Research Institute of Translational Neuroscience, Aarhus University, Aarhus, Denmark, ${ }^{2}$ Department \\ of Biomedicine, Aarhus University, Aarhus, Denmark
}

\section{OPEN ACCESS}

Edited by:

Fredric P. Manfredsson,

Michigan State University,

United States

Reviewed by:

Heather Jane Mortiboys,

The University of Sheffield,

United Kingdom

Nicola B. Mercuri,

Università degli Studi di Roma Tor Vergata, Italy

Gerardo Morfini,

The University of Illinois at Chicago,

United States

*Correspondence:

Poul Henning Jensen

phj@biomed.au.dk

Specialty section:

This article was submitted to

Neurodegeneration,

a section of the journal

Frontiers in Neuroscience

Received: 07 June 2018

Accepted: 19 October 2018

Published: 06 November 2018

Citation:

Betzer C and Jensen PH (2018)

Reduced Cytosolic Calcium as an

Early Decisive Cellular State in

Parkinson's Disease and

Synucleinopathies.

Front. Neurosci. 12:819.

doi: 10.3389/fnins.2018.00819
The more than 30-year-old Calcium hypothesis postulates that dysregulation in calcium dependent processes in the aging brain contributes to its increased vulnerability and this concept has been extended to Alzheimer's disease and Parkinson's disease. Central to the hypothesis is that increased levels of intracellular calcium develop and contributes to neuronal demise. We have studied the impact on cells encountering a gradual build-up of aggregated $\alpha$-synuclein, which is a central process to Parkinson's disease and other synucleinopathies. Surprisingly, we observed a yet unrecognized phase characterized by a reduced cytosolic calcium in cellular and neuronal models of Parkinson's disease, caused by $\alpha$-synuclein aggregates activating the endoplasmic calcium ATPase, SERCA. Counteracting the initial phase with low calcium rescues the subsequent degenerative phase with increased calcium and cell death - and demonstrates this early phase initiates decisive degenerative signals. In this review, we discuss our findings in relation to literature on calcium dysregulation in Parkinson's disease and dementia.

Keywords: aggregation, $\alpha$-synuclein, calcium, synucleinopathies, dementia

\section{INTRODUCTION}

In Parkinson's disease (PD), dopaminergic neurons in the substantia nigra pars compacta have been the focus of interest for decades due to their disease-associated loss that gives rise to the striatal dopamine deficiency and motoric symptoms. An intense interest in the cytosolic $\mathrm{Ca}^{2+}$ levels of these cells has been based on two independent lines of evidence. First, the autonomous firing of these dopaminergic (DA) neurons along with their large terminal fields causes a continuous and large influx of $\mathrm{Ca}^{2+}$ that in order to maintain low normal $\mathrm{Ca}^{2+}$ levels has to be balanced by active transport processes at the risk of oxidative stress (Surmeier, 2007; Dryanovski et al., 2013; Surmeier et al., 2017). Second, epidemiological studies have demonstrated that treatment with L-type $\mathrm{Ca}^{2+}$ channel antagonists that lowers $\mathrm{Ca}^{2+}$ influx reduces the risk of developing PD symptoms (Ritz et al., 2010; Pasternak et al., 2012). We recently reported a novel phenotype with reduced cytosolic $\mathrm{Ca}^{2+}$ in neurons that occurs very early in the degenerative processes associated to PD (Figure 1). In contrast to previous hypotheses focusing on loss of cells, this observation corroborates the existence of prolonged phase with reduced $\mathrm{Ca}^{2+}$ in neurons that encounter progressive build-up of $\alpha$-synuclein aggregates (Betzer et al., 2018). This phase may contribute to symptomatology by changing the neurons contribution to functional motor and non-motor circuitries. 


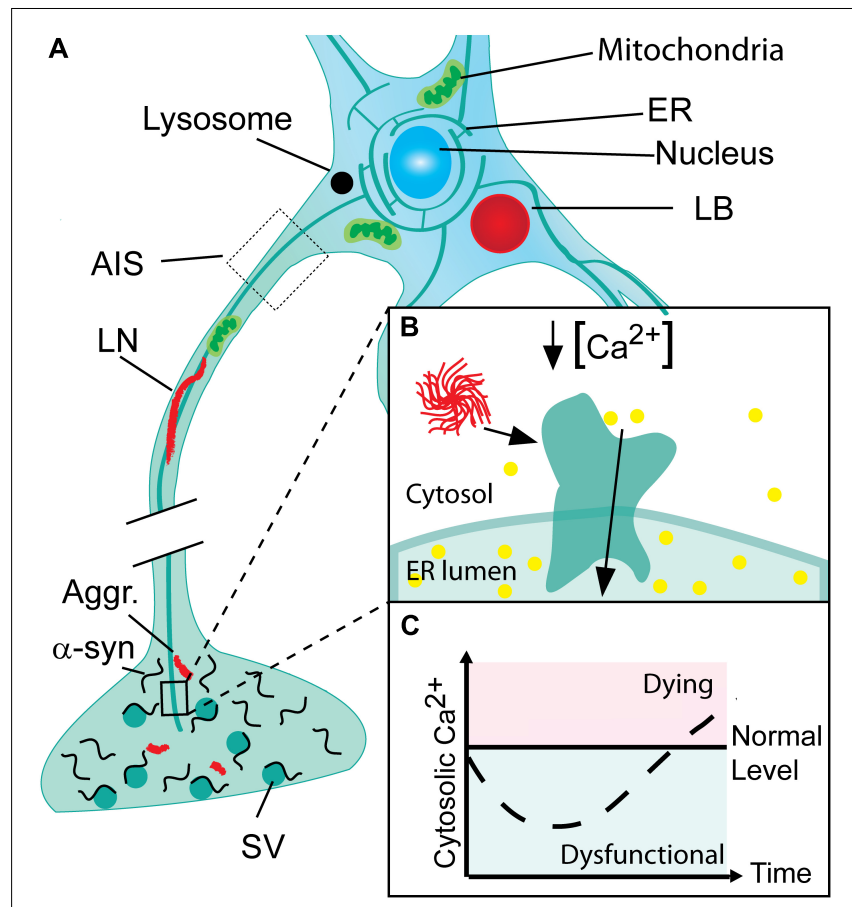

FIGURE 1 | Progressive neuronal accumulation of $\alpha$-synuclein aggregates in Parkinson's disease cause gradual activation of SERCA and changes in cytosolic $\mathrm{Ca}^{2+}$ and $\mathrm{Ca}^{2+}$ dependent processes. (A) Nerve terminals with their high concentration of $\alpha$-synuclein are the sites for the initial build-up of $\alpha$-synuclein ( $\alpha$-syn) aggregates (Aggr.). The aggregates are transported to the cell body by active retrograde axonal transport and during this process accumulate as Lewy neurites (LN). In the cell body, aggregates may accumulate locally as Lewy bodies (LB) if not degraded by lysosomes. (B) The endoplasmic reticulum (ER) permeates the entire neuron into its terminals. In Parkinson's disease (PD), $\alpha$-syn aggregates bind and activate SERCA resulting in reduced cytosolic $\mathrm{Ca}^{2+}$ and $\mathrm{Ca}^{2+}$ overload in the ER. (C) The cytosolic $\mathrm{Ca}^{2+}$ level in neurons encountering a progressive build-up of intracellular $\alpha$-synuclein aggregates displays a biphasic response with a reduced level in the early phase $\mathrm{Ca}^{2+}$ ions are translocated into the ER. This phase will be characterized by a range of dysfunctions caused by deranged $\mathrm{Ca}^{2+}$ dependent processes. Later the compensatory mechanisms fail and the cell progress into a degenerative state with increased $\mathrm{Ca}^{2+}$ that precede cell death.

\section{CYTOSOLIC CALCIUM IONS}

Calcium ions are versatile cellular second messengers and proper control of cytosolic $\mathrm{Ca}^{2+}$ levels in neurons are crucial for their development and function (Berridge et al., 2000, 2003). The resting cytosolic $\mathrm{Ca}^{2+}$ concentration in neurons is approximately $150 \mathrm{nM}$ but this term is a crude measure because most $\mathrm{Ca}^{2+}$ signaling is mediated within subcellular microdomains (Rizzuto and Pozzan, 2006). This is particularly true for neurons that are highly polarized with separate microdomains like nerve terminals, axon initial segment and synaptic boutons. Still the experimental use of cytosolic $\mathrm{Ca}^{2+}$ sensors like Fura-2 and Fluo3 have given important insights into neuronal $\mathrm{Ca}^{2+}$ signaling despite their suboptimal spatial resolution.

The average $150 \mathrm{nM}$ cytosolic $\mathrm{Ca}^{2+}$ contrasts the endoplasmic reticulum (ER) and the extracellular compartment where $\mathrm{Ca}^{2+}$ concentrations are in the $1 \mathrm{mM}$ range (Berridge et al., 2003; Surmeier and Schumacker, 2013) and these steep gradients are maintained by active transport through efficient pumps and secondary active cotransporters like sarcoplasmic/endoplasmic reticulum $\mathrm{Ca}^{2+}$ ATPases (SERCA), plasma membrane ATPases (PMCA), and $\mathrm{Na}^{+} / \mathrm{Ca}^{2+}$ exchangers (NCX).

It was early recognized that dysfunctions herein triggered by a broad range of cellular stresses, e.g., decreased ATP and $\mathrm{O}_{2}$, per default will increase cytosolic $\mathrm{Ca}^{2+}$ and ultimately cause cell death (Berridge et al., 1998). However, more subtle changes in leakiness or efficiency of specific pumps could also have fundamental, but slowly progressing effects on the brains ability to compensate with aging and age-related neurodegenerative diseases as put forth in the $\mathrm{Ca}^{2+}$-hypothesis (Khachaturian, 1984, 1994; Berridge, 2010).

\section{PARKINSON'S DISEASE AND $\alpha$-SYNUCLEIN}

Our insight into PD pathophysiology has developed significantly within the last 20 years since (i) mutations within the SNCA gene encoding $\alpha$-synuclein was identified as causative for autosomal dominant PD in rare families (Zeng et al., 2018), (ii) aggregated $\alpha$-synuclein was demonstrated as the main component in the neuronal Lewy body inclusions in PD (Spillantini et al., 1997), and (iii) the Braak hypothesis was presented (Braak et al., 2003) on PD being a progressive neurodegenerative disease that continuously involves new but selective areas of the brain thereby bringing increased complexity to the patients symptomatology. Today, it is commonly recognized that many PD patients have suffered from non-motor symptoms, e.g., depression and sleep disturbances, years before they develop motor symptoms leading to PD diagnosis (Figure 2). Hence, mechanisms applicable to larger groups of vulnerable neurons rather than the dopaminergic neurons of the substantia nigra pars compacta are attractive targets if the aim is to modify the disease course at different stages from presymptomatic to late-stage disease. The presymptomatic intervention is, as for all late-onset neurodegenerative diseases, especially attractive but requires strong biomarkers to identify at-risk patients. The spreading of pathology is hypothesized to be carried by prion-like aggregates of the normally presynaptic protein $\alpha$-synuclein that upon uptake in healthy neurons cause progressive conversion of their native $\alpha$-synuclein into aggregated species. The aggregated species represents a still poorly described group that initially are hypothesized to contain soluble, so-called oligomers or protofibrils, before they convert into amyloid-type filaments. The filaments are deposited in intracellular inclusions localized in axons and cell bodies as Lewy neurites and Lewy bodies that represents pathoanatomical hallmarks of PD (Figure 1). The process of $\alpha$-synuclein aggregation is dose-dependent as evidenced by the autosomal dominant heritability of PD in rare families with elevated levels of normal $\alpha$-synuclein caused by multiplications of the $\alpha$-synuclein gene SNCA (Singleton et al., 2003; Chartier-Harlin et al., 2004; Devine et al., 2011). Moreover, GWAS studies demonstrates variations in the SNCA 

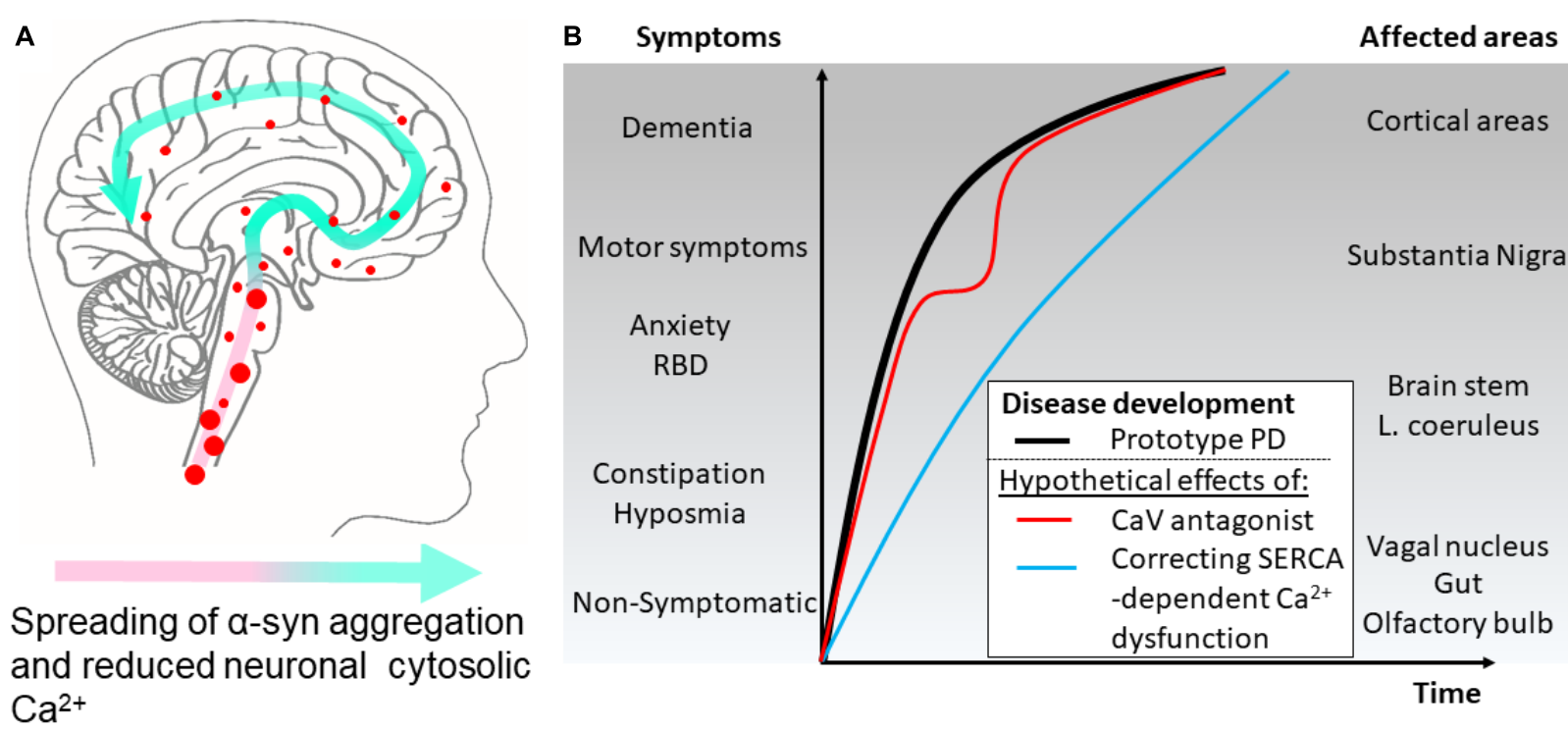

FIGURE 2 | Hypothetical effects on symptomatology in Parkinson's disease by modulating cytosolic calcium in neurons by different mechanisms. (A) The disease course for a Parkinson's disease patient can be divided into different phases. According to the Braak hypothesis, the phases represent the sweeping movement of $\alpha$-synuclein aggregate-dependent neuropathology through the nervous system and is initially detectable in the lower brain stem and the olfactory bulb. (B) The presymptomatic phase represent early aggregate build-up in the neurons of the olfactory bulb, the gut and the vagal motor nucleus of the lower brain stem and evolves into the symptomatic phase with hyposmia and constipation as frequent symptoms. Further involvement of the brain stem may add symptoms like sleep disturbances, e.g., REM sleep behavior disorders (RBD), depression, and anxiety. Next, the substantia nigra becomes involved and the patients develop motor symptoms and get diagnosed as PD patients. Finally, higher areas are involved adding cognitive problems to the disease complex. Treatment of patient with L-type $\mathrm{Ca}^{2+}$ channel antagonists aims at normalizing $\mathrm{Ca}^{2+}$ dysfunctions in the pace-making firing dopaminergic neurons of the substantia nigra pars compacta and other vulnerable neuronal populations. Epidemiological data suggest this treatment lowers the motoric symptoms but not the final progression into dementia as depicted by a red line. A treatment that targets the early $\mathrm{Ca}^{2+}$ dysfunctions caused by SERCA activation by $\alpha$-synuclein aggregates will ideally normalize the early dysfunctions of affected neurons. This could apart from reducing the severity of non-motor symptoms also decrease the rate of disease progression through the brain (blue line).

locus is the largest genetic risk factor for sporadic PD and this effect is hypothesized to be due to increased expression $\alpha$-synuclein. $\alpha$-Synuclein is thus considered a key player in the development and progression of PD although it still is unclear which intracellular $\alpha$-synuclein aggregates harm the neurons and how this is accomplished. Insight into the molecular structure of in vitro formed $\alpha$-synuclein aggregates has only recently reached the level of atomic resolution by CryoEM (Guerrero-Ferreira et al., 2018) and solid state NMR studies (Tuttle et al., 2016). The ability to validate that features of in vitro formed aggregates indeed exist in vivo has benefitted from the development of aggregate specific antibodies (Lindersson et al., 2004; Vaikath et al., 2015; Lassen et al., 2018; Peng et al., 2018) that allows the validation of specific epitopes on both types of aggregates. Biochemical and structural analyses of $\alpha$-synuclein aggregates isolated from brain tissue (Gai et al., 2000; Anderson et al., 2006) or cells are sparse but specific targets for $\alpha$-synuclein aggregates has been identified (Lindersson et al., 2004, 2005; Betzer et al., 2015, 2018; Mao et al., 2016).

We have previously demonstrated that decisive prodegenerative signals, like changes in gene expression and secreted signaling molecules are generated at early time points in human $\alpha$-synuclein expressing immortalized rat oligodendroglial cells (OLN-93) encountering a progressive build-up of soluble $\alpha$-synuclein aggregates (Kragh et al., 2009, 2013, 2014). These can be measured in the OLN-93 model at early time points, where no gross dysfunctions are apparent. Recent investigations of this early phase allowed us to demonstrate by use of the ratiometric calcium sensor, Fura- 2 that it is characterized by a reduction in cytosolic $\mathrm{Ca}^{2+}$ in both mitotic OLN-93 and a non-mitotic human neuroblastoma cell model (SH-SY5Y) of $\alpha$-synuclein aggregate stress, and in primary cultures of mouse hippocampal neurons expressing human $\alpha$-synuclein from the Thy1-a-Syn Line 61 (Betzer et al., 2018). The early phase with reduced cytosolic $\mathrm{Ca}^{2+}$ preceded the well-known late phase with increased cytosolic $\mathrm{Ca}^{2+}$ and increased cell death (Figure 1). Mechanistically the decreased cytosolic $\mathrm{Ca}^{2+}$ was caused by binding of soluble $\alpha$-synuclein aggregates to SERCA, leading to increased pumping of $\mathrm{Ca}^{2+}$ from cytosol into ER. The increased activity of SERCA was measured by in vitro assays using sarcoplasmic microsomes isolated from rabbit muscle as the source of SERCA. Here was measured an increased hydrolysis of ATP, transport of ${ }^{45} \mathrm{Ca}^{2+}$, and dephosphorylation rate of the pump. Furthermore, analysis of the rate of $\mathrm{Ca}^{2+}$ loading into ER in the OLN-93 cells expressing the calcium sensor aequorin in ER revealed an increased uptake in the presence of $\alpha$-synuclein aggregates. The $\mathrm{Ca}^{2+}$ dysregulation could be treated pharmacologically by the specific SERCA inhibitor cyclopiazonic acid (CPA) leading to reduced cell stress and increased viability in the OLN-93 model, SH-SY5Y model, in the hippocampal neurons, and an in vivo $\mathrm{C}$. elegans model, UA44 [baInl1; Pdat-1::AS, Pdat-1::GFP] expressing AS 
and GFP in their dopaminergic neurons. The protective CPA dose did not negatively affect the viability of control cells. The abnormal complexes between $\alpha$-synuclein aggregates and SERCA could be demonstrated by co-immunoprecipitation of SERCA from brain homogenates using in vitro formed soluble aggregates as bait and in situ in SH-SY5Y cells using anovel $\alpha$-synuclein/SERCA proximity ligation assay. The proximity ligation assay also revealed positive signals in human brain tissue affected by dementia with Lewy bodies, but not control tissue corroboration this novel mechanism of $\alpha$-synuclein aggregates engaging with SERCA is relevant to human pathology. Hence, the degenerative phase with reduced cytosolic $\mathrm{Ca}^{2+}$ may well be active in human brain. It should be stressed that the mechanisms, whereby $\alpha$-synuclein aggregates activates SERCA is not restricted to neurons but is generic and will occur in all cells experiencing intracellular $\alpha$-synuclein aggregates, since SERCA is ubiquitously expressed (Primeau et al., 2018). SERCA is expressed by three genes, ATP2A1, 2 and 3, and their isoform diversity is increased by alternative splicing, giving rise to 13 isoforms (Wuytack et al., 2002; Dally et al., 2010). The expression of SERCA isoforms exhibit both specificity with respect to developmental state and tissue, with SERCA2b and SERCA3 as the predominant isoforms in brain (Uhlen et al., 2015). It will thus apart from PD, Lewy body dementia, and Lewy body variant of Alzheimer's disease (AD), also occur in Multiple systems atrophy, where aggregates accumulate in oligodendrocytes (Gai et al., 1998; Spillantini et al., 1998) as modeled by our OLN-93 models (Betzer et al., 2018). In $\mathrm{PD}$, does astrocytes in proximity of LB containing neurons also contain $\alpha$-synuclein (Braak et al., 2007) but it does not appear to be aggregated and thus able to affect their SERCA pumps (Takemiya and Yamagata, 2013).

One may ask why this phase with reduced cytosolic $\mathrm{Ca}^{2+}$ have not been appreciated before? Firstly, the experimental focus has been on cell models to generate inclusion or pathology that resembles Lewy bodies e.g., phosphorylation of Ser129 on cellular $\alpha$-synuclein or insoluble $\alpha$-synuclein species. These phenomena likely require a significant build-up of $\alpha$-synuclein aggregates and may occur in the late degenerative stage with increased cytosolic $\mathrm{Ca}^{2+}$ and enhanced cell death. Secondly, methodologically it is not trivial to demonstrate a $20 \%$ decrease in basal cytosolic $\mathrm{Ca}^{2+}$ of $150 \mathrm{nM}$ if it is not the aim of the experiment. The genetically encoded $\mathrm{Ca}^{2+}$ sensors, like GCAMP6, are designed to demonstrate increases in $\mathrm{Ca}^{2+}$ as readouts for neuronal activity. To obtain quantitative measurement of reductions in cytosolic $\mathrm{Ca}^{2+}$, we used the ratiometric $\mathrm{Ca}^{2+}$-sensor Fura- 2 that is exited at 340 and $380 \mathrm{~nm}$ and has its emission quantified at $510 \mathrm{~nm}$, which upon calibration allows quantitative measurements. In our study, we chose a region of interest to measure the Fura2 signal in the cell body located outside the nucleus that may reflect neurons average cytosolic $\mathrm{Ca}^{2+}$ in the somatodendritic compartment.

Conclusively, when neurons and other cells, like oligodendrocytes in MSA, experience a progressive buildup of $\alpha$-synuclein aggregation we propose the existence of an early phase characterized by a decreased cytosolic $\mathrm{Ca}^{2+}$ and a degree of $\mathrm{Ca}^{2+}$ overload in their ER. This phase is not characterized by degenerative death promoting processes, but slowly developing dysfunctions in critical $\mathrm{Ca}^{2+}$ dependent processes that compromise the cells ability to contribute to its normal circuitries and thereby brain functions. We propose a neuron-centric mechanisms where $\mathrm{Ca}^{2+}$ dysfunctions initiates in neurons that contain the $\alpha$-synuclein aggregate but one can speculate if it also affect the tripartite synapse coupling neuron and glia (Eroglu and Barres, 2010). The so-called tripartite synapse consists of pre- and postsynaptic neuronal structures along with the astrocyte processes that connects hereto. The astrocytes contribute to the neuron-neuron signaling by releasing glial transmitters that bind to receptors on both pre- and postsynaptic neuronal structures (Eroglu and Barres, 2010). The SERCA activated dysfunctions in neurons may affect both the release of transmitters targeting astrocytes and the receptors that respond to the glial transmitters. Insight into these processes may allow direct targeting the abnormally activated SERCA pump or its downstream signaling pathways. This reorientation of focus from what kills the cells to what make them dysfunctional, may allow us to relieve symptoms caused by dysfunction of neurons and/or glia. Nerve cells often function as parts of closely regulated circuits that by support from glia cells contribute to brain functions and dysfunctions herein cause symptoms. A focus on alleviating cellular dysfunctions may open for more points of therapeutic intervention.

\section{EVIDENCE OF NEURONAL CALCIUM DISTURBANCES IN PD}

The $\mathrm{Ca}^{2+}$ hypothesis that originally was associated to aging (Khachaturian, 1984) and later AD (Berridge, 2010) has also rationally been adopted in the PD field. First, it was demonstrated that dopaminergic neurons in the substantia nigra pars compacta display autonomous pace-making firing and this combined with their extremely large terminal fields, results in a large influx of $\mathrm{Ca}^{2+}$ via L-type voltage-gated $\mathrm{Ca}^{2+}$ channels $(\mathrm{CaV})$ (Chan et al., 2007). Maintaining low normal $\mathrm{Ca}^{2+}$ levels by active transport processes requires large ATP production by oxidative phosphorylation and carries a risk of oxidative stress (Surmeier, 2007; Dryanovski et al., 2013; Surmeier et al., 2017). The CaV1.3 is largely responsible for the $\mathrm{Ca}^{2+}$ influx in pace-making neurons in substantia nigra and has been proposed to be involved in $\mathrm{Ca}^{2+}$ dysregulation since it does not fully close during autonomous firing (Wilson and Callaway, 2000; Bean, 2007; Puopolo et al., 2007; Surmeier and Schumacker, 2013).

Second, L-type $\mathrm{Ca}^{2+}$ channel blockers of the dihydropyridine type (DiCCBs) used to treat hypertension reduce the risk of developing PD and its associated mortality, but did not reduce the risk of dementia in PD patients (Becker et al., 2008; Ritz et al., 2010; Pasternak et al., 2012). The absent effect on cognition combined with a lack of association between length of previous use of $\mathrm{Ca}^{2+}$ channel blockers and its preventive effect, which made the authors suggest "any clinical effects of DiCCBs may be associated with symptomatic relief (preventing the development of clinical symptoms of early disease) rather than having a longterm impact on neurodegeneration" (Pasternak et al., 2012). However, changes to $\mathrm{CaV}$ channel expression has been reported 
in PD brains suggesting where a dysregulation was demonstrated by immunohistochemistry in early and late stage PD brains (Hurley et al., 2013). The study demonstrated abnormalities in $\mathrm{CaV}$ subtype expression with a general increase preceding PD pathology along with a change in the ratio of CaV1.2 vs. CaV1.3 to favor a greater utilization of CaV1.3 channels (Hurley et al., 2013). The mechanism governing these changes, which may allow increased $\mathrm{Ca}^{2+}$ influx are unknown, but could in principle be a response to decreased cytosolic $\mathrm{Ca}^{2+}$ in neurons. Clinical trials testing the $\mathrm{Ca}^{2+}$-hypothesis in $\mathrm{PD}$ are ongoing where the efficacy of CaV1.3 channel antagonist, Israpidine, is being evaluated ${ }^{1}$. However, even if the trials succeed in demonstrating symptomatic relief, they may not modify the progressive and widespread pathology that develops during the course of a PD patients life and which may be caused by prion-like properties of spreading $\alpha$-synuclein aggregates (Braak et al., 2003).

\section{IS INCREASED CYTOSOLIC CALCIUM ALWAYS BAD OR CAN IT EVEN BE NEUROPROTECTIVE?}

We demonstrated that development of $\alpha$-synuclein aggregates, by activating a $\mathrm{Ca}^{2+}$ pump, causes a decrease in cytosolic $\mathrm{Ca}^{2+}$. This demonstrates that not only increased $\mathrm{Ca}^{2+}$, as posited by the $\mathrm{Ca}^{2+}$-hypothesis, but also low $\mathrm{Ca}^{2+}$ can have adverse effects (Betzer et al., 2018). Considering the $\mathrm{Ca}^{2+}$-hypothesis, one may ask if increased cytosolic $\mathrm{Ca}^{2+}$ always is cytotoxic? Early studies focusing on developmental aspects of primary cultures of peripheral neurons demonstrated increasing intracellular $\mathrm{Ca}^{2+}$ levels by chronic depolarization was cytoprotective (Scott and Fisher, 1970; Franklin et al., 1995). This could also be demonstrated in vivo where activation of spiral ganglion neurons promoted their survival in the inner ear, which was prevented by blocking $\mathrm{Ca}^{2+}$ influx through L-type $\mathrm{Ca}^{2+}$ channels by Verapamil (Miller et al., 2003). Treatment with Verapamil was among the $\mathrm{CaV}$ channel antagonists that reduced the risk of developing PD symptomatology (Pasternak et al., 2012). A different neuroprotective mechanism has been demonstrated relying on synaptic stimulation of NMDA receptors (NMDAR) (Zhang et al., 2007). The NMDAR stimulation on dendritic spines, but not on extrasynaptic sites, triggers a signaling cascade that causes $\mathrm{Ca}^{2+}$ transients in the nucleus. The increase in nuclear $\mathrm{Ca}^{2+}$ stimulates transcription of specific genes, among some designated neuronal shield genes that contribute to enhanced neuronal survival and differentiation (Mao et al., 1999; Hardingham et al., 2002; Lee et al., 2005; Papadia et al., 2005; Bok et al., 2007; Zhang et al., 2007; Hardingham, 2009; Bading, 2013). In primary cultures of hippocampal neurons from $\alpha$-synuclein transgenic mice, we measured the decreased cytosolic $\mathrm{Ca}^{2+}$ in the somatodendritic compartment just outside the nucleus (Betzer et al., 2018). Considering the fenestrated nature of the nuclear membrane this will likely result in a decreased nuclear $\mathrm{Ca}^{2+}$ that may blunt the protective $\mathrm{Ca}^{2+}$ transient elicited by synaptic NMDAR signaling.

${ }^{1}$ https://www.clinicaltrials.gov/

\section{CALCIUM OVERLOAD OF THE ENDOPLASMIC RETICULUM}

When $\alpha$-synuclein aggregates activate SERCA, the transport of $\mathrm{Ca}^{2+}$ into the lumen of the ER is increased (Betzer et al., 2018). However, it is unclear how much this increases the $\mathrm{Ca}^{2+}$ load and the consequences hereof. Still it is becoming increasingly evident that the level of $\mathrm{Ca}^{2+}$ load in the ER plays fundamental roles for a range of important cellular processes. These processes comprise the unfolded protein response, the critical $\mathrm{Ca}^{2+}$ filling of mitochondria needed for oxidative phosphorylation, store-operate $\mathrm{Ca}^{2+}$ entry (SOCE) of $\mathrm{Ca}^{2+}$ across the plasma membrane into the ER (Carreras-Sureda et al., 2018) and the recently described regulation of presynaptic neurotransmitter release probability by axonal and presynaptic $\mathrm{ER} \mathrm{Ca}^{2+}$ filling (de Juan-Sanz et al., 2017), and specialized overload channels like TMCO1 has been identified that counteracts ER overload (Wang et al., 2016). The significance in these pathways in neurons encountering a gradual build-up of $\alpha$-synuclein aggregates needs further investigations.

\section{CALCIUM DYSREGULATION AND MITOCHONDRIA}

ER represents the major $\mathrm{Ca}^{2+}$ storage organelle but other organelles also play important roles in cellular $\mathrm{Ca}^{2+}$ homeostasis including mitochondria, Golgi apparatus, secretory vesicles, lysosomes, and peroxisomes (Rodriguez et al., 1997; Pinton et al., 1998; Mitchell et al., 2001; Saris and Carafoli, 2005; Rizzuto and Pozzan, 2006; Drago et al., 2008; Lasorsa et al., 2008). This suggests that $\alpha$-synuclein aggregate-dependent stimulation of SERCA may affects the functionality of these organelles by the increased $\mathrm{ER} \mathrm{Ca}^{2+}$-load and reduced cytosolic $\mathrm{Ca}^{2+}$ level.

Mitochondria has for long been considered a key player in PD pathogenesis as evidenced by their decreased complex 1 activity in PD patients (Schapira et al., 1989), the induction of a PD phenotype by the mitochondrial toxin MPTP (Langston et al., 1983), and the identification of mitochondria related PARK2 and PARK4 genes causing autosomal recessive PD (Kitada et al., 1998; Valente et al., 2004). $\mathrm{Ca}^{2+}$ influx into mitochondria is carried by diffusion through the voltage-dependent anion channel 1 (VDAC) in the outer mitochondrial membrane and through the mitochondrial $\mathrm{Ca}^{2+}$ uniporter (MCU) in the inner mitochondrial membrane (Bathori et al., 2006; Tan and Colombini, 2007). The efficiency of this process rely on the positioning of mitochondria in the proximity of the $\mathrm{Ca}^{2+}$-rich ER by means of mitochondrion-associated membrane (MAM) domains (Rizzuto et al., 2009). An estimate of up to $20 \%$ of the mitochondrial surface is in close proximity with the ER (Rizzuto et al., 1998) with a distance of 9-30 nm (Goetz and Nabi, 2006; Csordás et al., 2006). This correspond to the distance of protein complexes tethering the organellar membranes (Perkins et al., 1997). A tethering complex is formed between $\mathrm{ER} \mathrm{Ca}^{2+}$-channel, inositol 1, 4, 5-trisphosphate receptor (IP3R) and VDAC1 in the mitochondria by the action of the chaperone GRP75 and this facilitates the flux of $\mathrm{Ca}^{2+}$ from $\mathrm{ER}$ into mitochondria. 
Mitochondria are rich in the lipid cardiolipin that facilitates their $\alpha$-synuclein binding (Nakamura et al., 2011), and MAM is rich in negatively charged phospholipids (Hayashi and Fujimoto, 2010) that also facilitates binding of $\alpha$-synuclein (Davidson et al., 1998). The membrane binding ability of $\alpha$-synuclein and localization to MAM is abolished in $\alpha$-synuclein carrying the familial PD mutation A30P (Jensen et al., 1998; Guardia-Laguarta et al., 2014) and this is associated with decreased MAM activity and mitochondrial-ER interface (Guardia-Laguarta et al., 2014). This suggests a physiological function of native $\alpha$-synuclein in facilitating optimal ER-mitochondrial interactions. Aberrant forms of $\alpha$-synuclein have been demonstrated to affects mitochondrial function by disrupting the $\mathrm{Ca}^{2+}$ traffic at ERmitochondrial interphases (Cali et al., 2012; Guardia-Laguarta et al., 2014; Raffaello et al., 2016) and to increase ER and mitochondrial stress (Smith et al., 2005; Colla et al., 2012; Melachroinou et al., 2013). This may be caused by direct interactions between aberrant $\alpha$-synuclein forms and VDAC1 (McFarland et al., 2008; Martin et al., 2014; Betzer et al., 2015). However, the significance of these findings and if they only are active in certain species, cellular states and domains has been stressed by recent studies. Mouse neurons lacking $\alpha$-synuclein alone and all three synuclein forms did not demonstrate significant changes to mitochondrial bioenergetics (Pathak et al., 2017) whereas human iPSC derived neurons expressing mutant $\alpha$-synuclein displayed mitochondrial dysfunctions (Ryan et al., 2018). Hence, understanding the significance of $\alpha$-synuclein species interactions with mitochondria and MAM and their relation to the $\mathrm{Ca}^{2+}$ homeostasis of the involved organelles needs further investigations.

\section{$\alpha$-SYNUCLEIN AND AXONAL DYSFUNCTIONS IN PD.}

$\alpha$-synuclein is predominantly a presynaptic protein and its intraneuronal aggregation is likely initiated at this site (Kramer and Schulz-Schaeffer, 2007), which make the axonal transport regulating its anterograde and retrograde transport of key importance. How $\alpha$-synuclein aggregate dependent SERCA activation affects these processes are currently unknown, but the fundamental role of the $\mathrm{Ca}^{2+}$ content in the axonal ER makes $\alpha$-synuclein aggregation in this compartment especially critical (de Juan-Sanz et al., 2017). Moreover, $\alpha$-synuclein holds potential of affecting other axonal functions in PD. Axonal pathology is recognized in $\mathrm{PD}$ as swellings crowded with organelles shown by electron microscopic studies suggestive of compromised axonal flux (Vital et al., 2014). These finding are corroborated by kinetic analyses of axonally transported biomarkers in cerebrospinal fluids from PD patients (Fanara et al., 2012). The axonal accumulation of aggregated $\alpha$-synuclein in small, larger granules, and extended inclusions is the defining characteristic of Lewy neurites (Braak et al., 1999) that also can contain other axonally transported cargo like $\beta$-synuclein (Galvin et al., 1999) and such abnormalities have also been modeled in $\alpha$-synuclein transgenic mice (Games et al., 2013). The functional consequences of axonal $\alpha$-synuclein aggregates are not clear, but transgenic overexpression in neurons demonstrate dysfunctions in vesicle transport, e.g., of Rab7 containing endosomes (Volpicelli-Daley et al., 2014; Koch et al., 2015). $\alpha$-synuclein containing axonal structures associate to both anterograde kinesin-labeled and retrograde dynein-labeled structures in neurons (Utton et al., 2005) and early reductions in kinesin levels preceded reductions reduction of tyrosine hydroxylase in the dopamine neurons (Chu et al., 2012). Hypothesizing $\alpha$-synuclein aggregation predominantly initiates in the nerve terminals makes retrograde $\alpha$-synuclein transport processes of pivotal importance for the clearance (Jensen et al., 1999; Bieri et al., 2018). The retrograde transport is generally considered as an active transport of endosomes and autophagosomes pulled along the microtubules by the dynein motor complex and the process has achieved increased interest because of its involvement in transport of signaling complexes from nerve terminals (Zahavi et al., 2017). $\alpha$-Synuclein aggregates are able to directly target dynein complex components (Betzer et al., 2015) that may compromise retrograde transport and represent a basis for the accumulation of aggregated $\alpha$-synuclein in Lewy neurites. However, $\alpha$-synuclein may also affect other axonal mechanisms by e.g., directly affecting microtubule structures (Alim et al., 2004; Toba et al., 2017), and ER, and mitochondria, which both are organelles present in axons and nerve terminals (Gonzalez and Couve, 2014; Smith and Gallo, 2018). In PD, $\alpha$-synuclein aggregates accumulate directly on ER (Colla et al., 2012) where they can activate SERCA (Betzer et al., 2018), but they can also bind the ER protein, VAPB (Betzer et al., 2015) thereby disrupting the ERmitochondria tethering and affecting ATP production (Paillusson et al., 2017). Mechanistic studies that will allow a prioritization of these many interactions and mechanisms are in high demand to allow identification of potential disease modifying targets.

\section{ALZHEIMER DISEASE AND CALCIUM OVERLOAD OF THE ENDOPLASMIC RETICULUM}

The $\mathrm{Ca}^{2+}$-hypothesis has been widely embraced in the $\mathrm{AD}$ field where the moderate age-related $\mathrm{Ca}^{2+}$ remodeling is hypothesized to be pushed into severe $\mathrm{Ca}^{2+}$ signal remodeling by components of the amyloidogenic pathway central to AD (Berridge, 2010). Presenilins has turned out as central players in this model. Presenilins 1 and 2 are ER transmembrane proteins that regulate production of amyloidogenic $\mathrm{A} \beta$ peptides and causes familial $\mathrm{AD}$ in families when mutated (Tolia and De Strooper, 2009). Presenilins are, like aggregated $\alpha$-synuclein, activators of SERCA pumps (Green et al., 2008). This activity, which tend to increase ER $\mathrm{Ca}^{2+}$ levels, is balanced by the presenilins inherent function as low conductance $\mathrm{Ca}^{2+}$-leak channels that allows the $\mathrm{Ca}^{2+}$ ions to flow back into the cytosol (Tu et al., 2006). AD causing mutations in presenilin 1 blocks this $\mathrm{Ca}^{2+}$-leak activity thereby causing $\mathrm{ER} \mathrm{Ca}^{2+}$-overload with detrimental effects on ER-dependent signaling affecting store operated $\mathrm{Ca}^{2+}$ entry (SOCE), expression of ryanodine receptors (RyR), and inositol trisphosphate receptors (IP3R) (Blalock et al., 2003; Emilsson et al., 2006; Bezprozvanny, 2009; 
Popugaeva and Bezprozvanny, 2014). This bears resemblance to the situation that we have described for $\alpha$-synuclein aggregates. Their activation of SERCA will also tend to increase ER $\mathrm{Ca}^{2+}$ load and may therefore share some of these neurobiological effects. It will be motivated in $\alpha$-synuclein-aggregate dependent models to directly investigate if RyR. IP3R and SOCE functions are affected. SOCE has recently been demomstrated to play a central role in regulating the release probability in nerve terminals that are rich in $\alpha$-synuclein (de Juan-Sanz et al., 2017).

\section{HYPOTHESIS FOR NEURONAL DYSFUNCTIONS GENERATED BY $\alpha$-SYNUCLEIN AGGREGATES STIMULATION OF SERCA}

Aggregation of $\alpha$-synuclein in neurons is a progressive process sculpted by the local concentration of $\alpha$-synuclein, presence of prion-like $\alpha$-synuclein seeds, and proteostatic balances. When early soluble aggregated $\alpha$-synuclein species are formed, they will bind to and activate the SERCA pump in the ER. Blocking the $\alpha$-synuclein aggregate dependent activation

\section{REFERENCES}

Alim, M. A., Ma, Q. L., Takeda, K., Aizawa, T., Matsubara, M., Nakamura, M., et al. (2004). Demonstration of a role for alpha-synuclein as a functional microtubule-associated protein. J. Alzheimers Dis. 6, 435-442; discussion 443449. doi: 10.3233/JAD-2004-6412

Khachaturian, Z. S. (1994). Calcium hypothesis of Alzheimer's disease and brain aging. Ann. N. Y. Acad. Sci. 747, 1-11. doi: 10.1111/j.1749-6632.1994.tb44398.x

Anderson, J. P., Walker, D. E., Goldstein, J. M., de Laat, R., Banducci, K., Caccavello, R. J., et al. (2006). Phosphorylation of Ser-129 is the dominant pathological modification of alpha-synuclein in familial and sporadic Lewy body disease. J. Biol. Chem. 281, 29739-29752. doi: 10.1074/jbc.M600933200

Bading, H. (2013). Nuclear calcium signalling in the regulation of brain function. Nat. Rev. Neurosci. 14, 593-608. doi: 10.1038/nrn3531

Bathori, G., Csordas, G., Garcia-Perez, C., Davies, E., and Hajnoczky, G. (2006). $\mathrm{Ca} 2+$-dependent control of the permeability properties of the mitochondrial outer membrane and voltage-dependent anion-selective channel (VDAC). J. Biol. Chem. 281, 17347-17358. doi: 10.1074/jbc.M600906200

Bean, B. P. (2007). Neurophysiology: stressful pacemaking. Nature 447, 1059-1060. doi: 10.1038/4471059a

Becker, C., Jick, S. S., and Meier, C. R. (2008). Use of antihypertensives and the risk of Parkinson disease. Neurology 70, 1438-1444. doi: 10.1212/01.wnl. 0000303818.38960 .44

Berridge, M. J. (2010). Calcium hypothesis of Alzheimer's disease. Pflugers Arch. 459, 441-449. doi: 10.1007/s00424-009-0736-1

Berridge, M. J., Bootman, M. D., and Lipp, P. (1998). Calcium-a life and death signal. Nature 395, 645-648. doi: 10.1038/27094

Berridge, M. J., Bootman, M. D., and Roderick, H. L. (2003). Calcium signalling: dynamics, homeostasis and remodelling. Nat. Rev. Mol. Cell Biol. 4, 517-529. doi: $10.1038 / \mathrm{nrm} 1155$

Berridge, M. J., Lipp, P., and Bootman, M. D. (2000). The versatility and universality of calcium signalling. Nat. Rev. Mol. Cell Biol. 1, 11-21. doi: 10. 1038/35036035

Betzer, C., Lassen, L. B., Olsen, A., Kofoed, R. H., Reimer, L., Gregersen, E., et al. (2018). Alpha-synuclein aggregates activate calcium pump SERCA leading to calcium dysregulation. EMBO Rep. 19:e44617. doi: 10.15252/embr.201744617

Betzer, C., Movius, A. J., Shi, M., Gai, W. P., Zhang, J., and Jensen, P. H. (2015). Identification of synaptosomal proteins binding to monomeric and oligomeric alpha-synuclein. PLoS One 10:e0116473. doi: 10.1371/journal.pone.0116473 by SERCA antagonists protected the affected neurons, thus demonstrating the existence of pivotal downstream signaling pathways. The ER is a dynamic organelle that permeates neurons from nerve terminals through axons, cell bodies into dendritic spines (Toresson and Grant, 2005) and this opens for several independent dysfunctions separated in space and time that contribute to the neurodegenerative process (Figure 1). Further insight into the contribution of SERCA-activated $\mathrm{Ca}^{2+}$ dysfunctions will open for novel mechanisms to counter the dysfunction associated to PD and other synucleinopathies.

\section{AUTHOR CONTRIBUTIONS}

$\mathrm{CB}$ and $\mathrm{PJ}$ designed and wrote the manuscript.

\section{FUNDING}

The work was supported by the Lundbeck Foundation (Grant nos. R223-2015-4222 and R248-2016-2518), Danish Research Institute of Translational Neuroscience - Dandrite, and Aarhus University.

Bezprozvanny, I. (2009). Calcium signaling and neurodegenerative diseases. Trends Mol. Med. 15, 89-100. doi: 10.1016/j.molmed.2009.01.001

Bieri, G., Gitler, A. D., and Brahic, M. (2018). Internalization, axonal transport and release of fibrillar forms of alpha-synuclein. Neurobiol. Dis. 109, 219-225. doi: 10.1016/j.nbd.2017.03.007

Blalock, E. M., Chen, K. C., Sharrow, K., Herman, J. P., Porter, N. M., Foster, T. C., et al. (2003). Gene microarrays in hippocampal aging: statistical profiling identifies novel processes correlated with cognitive impairment. J. Neurosci. 23, 3807-3819. doi: 10.1523/JNEUROSCI.23-09-03807.2003

Bok, J., Wang, Q., Huang, J., and Green, S. H. (2007). CaMKII and CaMKIV mediate distinct prosurvival signaling pathways in response to depolarization in neurons. Mol. Cell. Neurosci. 36, 13-26. doi: 10.1016/j.mcn.2007. 05.008

Braak, H., Rub, U., Gai, W. P., and Del Tredici, K. (2003). Idiopathic Parkinson's disease: possible routes by which vulnerable neuronal types may be subject to neuroinvasion by an unknown pathogen. J. Neural. Transm. 110, 517-536. doi: 10.1007/s00702-002-0808-2

Braak, H., Sandmann-Keil, D., Gai, W., and Braak, E. (1999). Extensive axonal Lewy neurites in Parkinson's disease: a novel pathological feature revealed by alpha-synuclein immunocytochemistry. Neurosci. Lett. 265, 67-69. doi: 10. 1016/S0304-3940(99)00208-6

Braak, H., Sastre, M., and Del Tredici, K. (2007). Development of alpha-synuclein immunoreactive astrocytes in the forebrain parallels stages of intraneuronal pathology in sporadic Parkinson's disease. Acta Neuropathol. 114, 231-241. doi: 10.1007/s00401-007-0244-3

Cali, T., Ottolini, D., Negro, A., and Brini, M. (2012). alpha-Synuclein controls mitochondrial calcium homeostasis by enhancing endoplasmic reticulummitochondria interactions. J. Biol. Chem. 287, 17914-17929. doi: 10.1074/jbc. M111.302794

Carreras-Sureda, A., Pihan, P., and Hetz, C. (2018). Calcium signaling at the endoplasmic reticulum: fine-tuning stress responses. Cell Calcium 70, 24-31. doi: 10.1016/j.ceca.2017.08.004

Chan, C. S., Guzman, J. N., Ilijic, E., Mercer, J. N., Rick, C., Tkatch, T., et al. (2007). 'Rejuvenation' protects neurons in mouse models of Parkinson's disease. Nature 447, 1081-1086. doi: 10.1038/nature05865

Chartier-Harlin, M. C., Kachergus, J., Roumier, C., Mouroux, V., Douay, X., Lincoln, S., et al. (2004). Alpha-synuclein locus duplication as a cause of familial Parkinson's disease. Lancet 364, 1167-1169. doi: 10.1016/S01406736(04)17103-1 
Chu, Y., Morfini, G. A., Langhamer, L. B., He, Y., Brady, S. T., and Kordower, J. H. (2012). Alterations in axonal transport motor proteins in sporadic and experimental Parkinson's disease. Brain 135, 2058-2073. doi: 10.1093/brain/ aws 133

Colla, E., Jensen, P. H., Pletnikova, O., Troncoso, J. C., Glabe, C., and Lee, M. K. (2012). Accumulation of toxic alpha-synuclein oligomer within endoplasmic reticulum occurs in alpha-synucleinopathy in vivo. J. Neurosci. 32, 3301-3305. doi: 10.1523/JNEUROSCI.5368-11.2012

Csordás, G., Renken, C., Várnai, P., Walter, L., Weaver, D., Buttle, K.F., et al. (2006). Structural and functional features and significance of the physical linkage between ER and mitochondria. J. Cell Biol. 174, 915-921. doi: 10.1083/jcb. 200604016

Dally, S., Corvazier, E., Bredoux, R., Bobe, R., and Enouf, J. (2010). Multiple and diverse coexpression, location, and regulation of additional SERCA2 and SERCA3 isoforms in nonfailing and failing human heart. J. Mol. Cell. Cardiol. 48, 633-644. doi: 10.1016/j.yjmcc.2009.11.012

Davidson, W. S., Jonas, A., Clayton, D. F., and George, J. M. (1998). Stabilization of alpha-synuclein secondary structure upon binding to synthetic membranes. J. Biol. Chem. 273, 9443-9449. doi: 10.1074/jbc.273.16.9443

de Juan-Sanz, J., Holt, G. T., Schreiter, E. R., de Juan, F., Kim, D. S., and Ryan, T. A. (2017). Axonal endoplasmic reticulum $\mathrm{Ca}(2+)$ content controls release probability in CNS nerve terminals. Neuron 93:e6. doi: 10.1016/j.neuron.2017. 01.010

Devine, M. J., Gwinn, K., Singleton, A., and Hardy, J. (2011). Parkinson's disease and alpha-synuclein expression. Mov. Disord. 26, 2160-2168. doi: 10.1002/mds. 23948

Drago, I., Giacomello, M., Pizzo, P., and Pozzan, T. (2008). Calcium dynamics in the peroxisomal lumen of living cells. J. Biol. Chem. 283, 14384-14390. doi: 10.1074/jbc.M800600200

Dryanovski, D. I., Guzman, J. N., Xie, Z., Galteri, D. J., Volpicelli-Daley, L. A., Lee, V. M., et al. (2013). Calcium entry and alpha-synuclein inclusions elevate dendritic mitochondrial oxidant stress in dopaminergic neurons. J. Neurosci. 33, 10154-10164. doi: 10.1523/JNEUROSCI.5311-12.2013

Emilsson, L., Saetre, P., and Jazin, E. (2006). Alzheimer's disease: mRNA expression profiles of multiple patients show alterations of genes involved with calcium signaling. Neurobiol. Dis. 21, 618-625. doi: 10.1016/j.nbd.2005.09.004

Eroglu, C., and Barres, B. A. (2010). Regulation of synaptic connectivity by glia. Nature 468, 223-231. doi: 10.1038/nature09612

Fanara, P., Wong, P. Y., Husted, K. H., Liu, S., Liu, V. M., Kohlstaedt, L. A., et al. (2012). Cerebrospinal fluid-based kinetic biomarkers of axonal transport in monitoring neurodegeneration. J. Clin. Invest. 122, 3159-3169. doi: 10.1172/ JCI64575

Franklin, J. L., Sanz-Rodriguez, C., Juhasz, A., Deckwerth, T. L., and Johnson, E. M Jr. (1995). Chronic depolarization prevents programmed death of sympathetic neurons in vitro but does not support growth: requirement for $\mathrm{Ca} 2+$ influx but not Trk activation. J. Neurosci. 15, 643-664. doi: 10.1523/JNEUROSCI.15-0100643.1995

Gai, W. P., Power, J. H., Blumbergs, P. C., and Blessing, W. W. (1998). Multiplesystem atrophy: a new alpha-synuclein disease? Lancet 352, 547-548. doi: 10. 1016/S0140-6736(05)79256-4

Gai, W. P., Yuan, H. X., Li, X. Q., Power, J. T., Blumbergs, P. C., and Jensen, P. H. (2000). In situ and in vitro study of colocalization and segregation of alphasynuclein, ubiquitin, and lipids in Lewy bodies. Exp. Neurol. 166, 324-333. doi: 10.1006/exnr.2000.7527

Galvin, J. E., Uryu, K., Lee, V. M., and Trojanowski, J. Q. (1999). Axon pathology in Parkinson's disease and Lewy body dementia hippocampus contains alpha-, beta-, and gamma-synuclein. Proc. Natl. Acad. Sci. U.S.A. 96, 13450-13455. doi: 10.1073/pnas.96.23.13450

Games, D., Seubert, P., Rockenstein, E., Patrick, C., Trejo, M., Ubhi, K., et al. (2013). Axonopathy in an alpha-synuclein transgenic model of Lewy body disease is associated with extensive accumulation of C-terminal-truncated alpha-synuclein. Am. J. Pathol. 182, 940-953. doi: 10.1016/j.ajpath.2012.11.018

Goetz, J. G., and Nabi, I. R. (2006). Interaction of the smooth endoplasmic reticulum and mitochondria. Biochem. Soc. Trans. 34, 370-373. doi: 10.1042/ BST0340370

Gonzalez, C., and Couve, A. (2014). The axonal endoplasmic reticulum and protein trafficking: cellular bootlegging south of the soma. Semin. Cell Dev. Biol. 27, 23-31. doi: 10.1016/j.semcdb.2013.12.004
Green, K. N., Demuro, A., Akbari, Y., Hitt, B. D., Smith, I. F., Parker, I., et al. (2008). SERCA pump activity is physiologically regulated by presenilin and regulates amyloid beta production. J. Gen. Physiol. 132, 1107-1116. doi: 10. 1085/JGP1322OIA1

Guardia-Laguarta, C., Area-Gomez, E., Rub, C., Liu, Y., Magrane, J., Becker, D., et al. (2014). alpha-Synuclein is localized to mitochondria-associated ER membranes. J. Neurosci. 34, 249-259. doi: 10.1523/JNEUROSCI.2507-13.2014

Guerrero-Ferreira, R., Taylor, N. M., Mona, D., Ringler, P., Lauer, M. E., Riek, R., et al. (2018). Cryo-EM structure of alpha-synuclein fibrils. bioRxiv 7:e36402. doi: 10.7554/eLife.36402

Hardingham, G. E. (2009). Coupling of the NMDA receptor to neuroprotective and neurodestructive events. Biochem. Soc. Trans. 37, 1147-1160. doi: 10.1042/ BST0371147

Hardingham, G. E., Fukunaga, Y., and Bading, H. (2002). Extrasynaptic NMDARs oppose synaptic NMDARs by triggering CREB shut-off and cell death pathways. Nat. Neurosci. 5, 405-414. doi: 10.1038/nn835

Hayashi, T., and Fujimoto, M. (2010). Detergent-resistant microdomains determine the localization of sigma-1 receptors to the endoplasmic reticulummitochondria junction. Mol. Pharmacol. 77, 517-528. doi: 10.1124/mol.109. 062539

Hurley, M. J., Brandon, B., Gentleman, S. M., and Dexter, D. T. (2013). Parkinson's disease is associated with altered expression of $\mathrm{CaV} 1$ channels and calciumbinding proteins. Brain 136, 2077-2097. doi: 10.1093/brain/awt134

Jensen, P. H., Li, J. Y., Dahlstrom, A., and Dotti, C. G. (1999). Axonal transport of synucleins is mediated by all rate components. Eur. J. Neurosci. 11, 3369-3376. doi: 10.1046/j.1460-9568.1999.00754.x

Jensen, P. H., Nielsen, M. S., Jakes, R., Dotti, C. G., and Goedert, M. (1998). Binding of alpha-synuclein to brain vesicles is abolished by familial Parkinson's disease mutation. J. Biol. Chem. 273, 26292-26294. doi: 10.1074/jbc.273.41.26292

Khachaturian, Z. S. (1984). "Towards theories of brain aging," in Handbook of Studies on Psychiatry and Old Age, eds D. S. Kay and G. W. Burrows (Amsterdam: Elsevier).

Kitada, T., Asakawa, S., Hattori, N., Matsumine, H., Yamamura, Y., Minoshima, S., et al. (1998). Mutations in the parkin gene cause autosomal recessive juvenile parkinsonism. Nature 392, 605-608. doi: 10.1038/33416

Koch, J. C., Bitow, F., Haack, J., d'Hedouville, Z., Zhang, J. N., Tonges, L., et al. (2015). Alpha-Synuclein affects neurite morphology, autophagy, vesicle transport and axonal degeneration in CNS neurons. Cell Death Dis. 6:e1811. doi: $10.1038 /$ cddis.2015.169

Kragh, C. L., Fillon, G., Gysbers, A., Hansen, H. D., Neumann, M., RichterLandsberg, C., et al. (2013). FAS-dependent cell death in alpha-synuclein transgenic oligodendrocyte models of multiple system atrophy. PLoS One 8:e55243. doi: 10.1371/journal.pone.0055243

Kragh, C. L., Gysbers, A. M., Rockenstein, E., Murphy, K., Halliday, G. M., Masliah, E., et al. (2014). Prodegenerative IkappaBalpha expression in oligodendroglial alpha-synuclein models of multiple system atrophy. Neurobiol. Dis. 63, 171-183. doi: 10.1016/j.nbd.2013.12.002

Kragh, C. L., Lund, L. B., Febbraro, F., Hansen, H. D., Gai, W. P., El-Agnaf, O., et al. (2009). Alpha-synuclein aggregation and Ser-129 phosphorylation-dependent cell death in oligodendroglial cells. J. Biol. Chem. 284, 10211-10222. doi: 10. 1074/jbc.M809671200

Kramer, M. L., and Schulz-Schaeffer, W. J. (2007). Presynaptic alpha-synuclein aggregates, not Lewy bodies, cause neurodegeneration in dementia with Lewy bodies. J. Neurosci. 27, 1405-1410. doi: 10.1523/JNEUROSCI.4564-06.2007

Langston, J. W., Ballard, P., Tetrud, J. W., and Irwin, I. (1983). Chronic Parkinsonism in humans due to a product of meperidine-analog synthesis. Science 219, 979-980. doi: 10.1126/science.6823561

Lasorsa, F. M., Pinton, P., Palmieri, L., Scarcia, P., Rottensteiner, H., Rizzuto, R., et al. (2008). Peroxisomes as novel players in cell calcium homeostasis. J. Biol. Chem. 283, 15300-15308. doi: 10.1074/jbc.M800648200

Lassen, L. B., Gregersen, E., Isager, A. K., Betzer, C., Kofoed, R. H., and Jensen, P. H. (2018). ELISA method to detect alpha-synuclein oligomers in cell and animal models. PLoS One 13:e0196056. doi: 10.1371/journal.pone.0196056

Lee, B., Butcher, G. Q., Hoyt, K. R., Impey, S., and Obrietan, K. (2005). Activitydependent neuroprotection and cAMP response element-binding protein (CREB): kinase coupling, stimulus intensity, and temporal regulation of CREB phosphorylation at serine 133. J. Neurosci. 25, 1137-1148. doi: 10.1523/ JNEUROSCI.4288-04.2005 
Lindersson, E., Beedholm, R., Hojrup, P., Moos, T., Gai, W., Hendil, K. B., et al. (2004). Proteasomal inhibition by alpha-synuclein filaments and oligomers. J. Biol. Chem. 279, 12924-12934. doi: 10.1074/jbc.M306390200

Lindersson, E., Lundvig, D., Petersen, C., Madsen, P., Nyengaard, J. R., Hojrup, P., et al. (2005). p25alpha Stimulates alpha-synuclein aggregation and is colocalized with aggregated alpha-synuclein in alpha-synucleinopathies. J. Biol. Chem. 280, 5703-5715. doi: 10.1074/jbc.M410409200

Mao, X., Ou, M. T., Karuppagounder, S. S., Kam, T. I., Yin, X., Xiong, Y., et al. (2016). Pathological alpha-synuclein transmission initiated by binding lymphocyte-activation gene 3. Science 353:aah3374. doi: 10.1126/science. aah3374

Mao, Z., Bonni, A., Xia, F., Nadal-Vicens, M., and Greenberg, M. E. (1999). Neuronal activity-dependent cell survival mediated by transcription factor MEF2. Science 286, 785-790. doi: 10.1126/science.286.5440.785

Martin, L. J., Semenkow, S., Hanaford, A., and Wong, M. (2014). Mitochondrial permeability transition pore regulates Parkinson's disease development in mutant alpha-synuclein transgenic mice. Neurobiol. Aging 35, 1132-1152. doi: 10.1016/j.neurobiolaging.2013.11.008

McFarland, M. A., Ellis, C. E., Markey, S. P., and Nussbaum, R. L. (2008). Proteomics analysis identifies phosphorylation-dependent alpha-synuclein protein interactions. Mol. Cell. Proteomics 7, 2123-2137. doi: 10.1074/mcp. M800116-MCP200

Melachroinou, K., Xilouri, M., Emmanouilidou, E., Masgrau, R., Papazafiri, P., Stefanis, L., et al. (2013). Deregulation of calcium homeostasis mediates secreted alpha-synuclein-induced neurotoxicity. Neurobiol. Aging 34, 2853-2865. doi: 10.1016/j.neurobiolaging.2013.06.006

Miller, A. L., Prieskorn, D. M., Altschuler, R. A., and Miller, J. M. (2003). Mechanism of electrical stimulation-induced neuroprotection: effects of verapamil on protection of primary auditory afferents. Brain Res. 966, 218-230. doi: 10.1016/S0006-8993(02)04170-7

Mitchell, K. J., Pinton, P., Varadi, A., Tacchetti, C., Ainscow, E. K., Pozzan, T., et al. (2001). Dense core secretory vesicles revealed as a dynamic $\mathrm{Ca}(2+)$ store in neuroendocrine cells with a vesicle-associated membrane protein aequorin chimaera. J. Cell. Biol. 155, 41-51. doi: 10.1083/jcb.200103145

Nakamura, K., Nemani, V. M., Azarbal, F., Skibinski, G., Levy, J. M., Egami, K., et al. (2011). Direct membrane association drives mitochondrial fission by the Parkinson disease-associated protein alpha-synuclein. J. Biol. Chem. 286, 20710-20726. doi: 10.1074/jbc.M110.213538

Paillusson, S., Gomez-Suaga, P., Stoica, R., Little, D., Gissen, P., Devine, M. J., et al. (2017). alpha-Synuclein binds to the ER-mitochondria tethering protein VAPB to disrupt $\mathrm{Ca}(2+)$ homeostasis and mitochondrial ATP production. Acta Neuropathol. 134, 129-149. doi: 10.1007/s00401-017-1704-z

Papadia, S., Stevenson, P., Hardingham, N. R., Bading, H., and Hardingham, G. E. (2005). Nuclear Ca2+ and the cAMP response element-binding protein family mediate a late phase of activity-dependent neuroprotection. J. Neurosci. 25, 4279-4287. doi: 10.1523/JNEUROSCI.5019-04.2005

Pasternak, B., Svanstrom, H., Nielsen, N. M., Fugger, L., Melbye, M., and Hviid, A. (2012). Use of calcium channel blockers and Parkinson's disease. Am. J. Epidemiol. 175, 627-635. doi: 10.1093/aje/kwr362

Pathak, D., Berthet, A., Bendor, J. T., Yu, K., Sellnow, R. C., Orr, A. L., et al. (2017). Loss of alpha-Synuclein Does Not Affect Mitochondrial Bioenergetics in Rodent Neurons. eNeuro 4:LENEURO.0216-16.2017. doi: 10.1523/ENEURO.0216-16. 2017

Peng, C., Gathagan, R. J., Covell, D. J., Medellin, C., Stieber, A., Robinson, J. L., et al. (2018). Cellular milieu imparts distinct pathological alpha-synuclein strains in alpha-synucleinopathies. Nature 557, 558-563. doi: 10.1038/s41586-0180104-4

Perkins, G., Renken, C., Martone, M. E., Young, S. J., Ellisman, M., and Frey, T. (1997). Electron tomography of neuronal mitochondria: three-dimensional structure and organization of cristae and membrane contacts. J. Struct. Biol. 119, 260-272. doi: 10.1006/jsbi.1997.3885

Pinton, P., Pozzan, T., and Rizzuto, R. (1998). The Golgi apparatus is an inositol 1,4,5-trisphosphate-sensitive $\mathrm{Ca} 2+$ store, with functional properties distinct from those of the endoplasmic reticulum. EMBO J. 17, 5298-5308. doi: 10.1093/ emboj/17.18.5298

Popugaeva, E., and Bezprozvanny, I. (2014). Can the calcium hypothesis explain synaptic loss in Alzheimer's disease? Neurodegener. Dis. 13, 139-141. doi: 10. $1159 / 000354778$
Primeau, J. O., Armanious, G. P., Fisher, M. E., and Young, H. S. (2018). The sarcoendoplasmic reticulum calcium ATPase. Subcell. Biochem. 87, 229-258. doi: 10.1007/978-981-10-7757-9_8

Puopolo, M., Raviola, E., and Bean, B. P. (2007). Roles of subthreshold calcium current and sodium current in spontaneous firing of mouse midbrain dopamine neurons. J. Neurosci. 27, 645-656. doi: 10.1523/JNEUROSCI.434106.2007

Raffaello, A., Mammucari, C., Gherardi, G., and Rizzuto, R. (2016). Calcium at the center of cell signaling: interplay between endoplasmic reticulum, mitochondria, and Lysosomes. Trends Biochem. Sci. 41, 1035-1049. doi: 10. 1016/j.tibs.2016.09.001

Ritz, B., Rhodes, S. L., Qian, L., Schernhammer, E., Olsen, J. H., and Friis, S. (2010). L-type calcium channel blockers and Parkinson disease in Denmark. Ann. Neurol. 67, 600-606. doi: 10.1002/ana.21937

Rizzuto, R., Marchi, S., Bonora, M., Aguiari, P., Bononi, A., De Stefani, D., et al. (2009). $\mathrm{Ca}(2+)$ transfer from the ER to mitochondria: when, how and why. Biochim. Biophys. Acta 1787, 1342-1351. doi: 10.1016/j.bbabio.2009.03.015

Rizzuto, R., Pinton, P., Carrington, W., Fay, F. S., Fogarty, K. E., Lifshitz, L. M., et al. (1998). Close contacts with the endoplasmic reticulum as determinants of mitochondrial Ca2+ responses. Science 280, 1763-1766. doi: 10.1126/science. 280.5370 .1763

Rizzuto, R., and Pozzan, T. (2006). Microdomains of intracellular Ca2+: molecular determinants and functional consequences. Physiol. Rev. 86, 369-408. doi: 10. 1152/physrev.00004.2005

Rodriguez, A., Webster, P., Ortego, J., and Andrews, N. W. (1997). Lysosomes behave as Ca2+-regulated exocytic vesicles in fibroblasts and epithelial cells. J. Cell Biol. 137, 93-104. doi: 10.1083/jcb.137.1.93

Ryan, T., Bamm, V. V., Stykel, M. G., Coackley, C. L., Humphries, K. M., JamiesonWilliams, R., et al. (2018). Cardiolipin exposure on the outer mitochondrial membrane modulates alpha-synuclein. Nat. Commun. 9:817. doi: 10.1038/ s41467-018-03241-9

Saris, N. E., and Carafoli, E. (2005). A historical review of cellular calcium handling, with emphasis on mitochondria. Biochemistry 70, 187-194.

Schapira, A. H., Cooper, J. M., Dexter, D., Jenner, P., Clark, J. B., and Marsden, C. D. (1989). Mitochondrial complex I deficiency in Parkinson's disease. Lancet 1:1269. doi: 10.1016/S0140-6736(89)92366-0

Scott, B. S., and Fisher, K. C. (1970). Potassium concentration and number of neurons in cultures of dissociated ganglia. Exp. Neurol. 27, 16-22. doi: 10.1016/ 0014-4886(70)90197-4

Singleton, A. B., Farrer, M., Johnson, J., Singleton, A., Hague, S., Kachergus, J., et al. (2003). alpha-Synuclein locus triplication causes Parkinson's disease. Science 302:841. doi: 10.1126/science.1090278

Smith, G. M., and Gallo, G. (2018). The role of mitochondria in axon development and regeneration. Dev. Neurobiol. 78, 221-237. doi: 10.1002/dneu.22546

Smith, W. W., Jiang, H., Pei, Z., Tanaka, Y., Morita, H., Sawa, A., et al. (2005). Endoplasmic reticulum stress and mitochondrial cell death pathways mediate A53T mutant alpha-synuclein-induced toxicity. Hum. Mol. Genet. 14, 38013811. doi: 10.1093/hmg/ddi396

Spillantini, M. G., Crowther, R. A., Jakes, R., Cairns, N. J., Lantos, P. L., and Goedert, M. (1998). Filamentous alpha-synuclein inclusions link multiple system atrophy with Parkinson's disease and dementia with Lewy bodies. Neurosci. Lett. 251, 205-208. doi: 10.1016/S0304-3940(98)00504-7

Spillantini, M. G., Schmidt, M. L., Lee, V. M., Trojanowski, J. Q., Jakes, R., and Goedert, M. (1997). Alpha-synuclein in Lewy bodies. Nature 388, 839-840. doi: $10.1038 / 42166$

Surmeier, D. J. (2007). Calcium, ageing, and neuronal vulnerability in Parkinson's disease. Lancet Neurol. 6, 933-938. doi: 10.1016/S1474-4422(07)70246-6

Surmeier, D. J., Obeso, J. A., and Halliday, G. M. (2017). Selective neuronal vulnerability in Parkinson disease. Nat. Rev. Neurosci. 18, 101-113. doi: 10. 1038/nrn.2016.178

Surmeier, D. J., and Schumacker, P. T. (2013). Calcium, bioenergetics, and neuronal vulnerability in Parkinson's disease. J. Biol. Chem. 288, 10736-10741. doi: 10. 1074/jbc.R112.410530

Takemiya, T., and Yamagata, K. (2013). Intercellular signaling pathway among Endothelia, astrocytes and neurons in excitatory neuronal damage. Int. J. Mol. Sci. 14, 8345-8357. doi: 10.3390/ijms14048345

Tan, W., and Colombini, M. (2007). VDAC closure increases calcium ion flux. Biochim. Biophys. Acta 1768, 2510-2515. doi: 10.1016/j.bbamem.2007.06.002 
Toba, S., Jin, M., Yamada, M., Kumamoto, K., Matsumoto, S., Yasunaga, T., et al. (2017). Alpha-synuclein facilitates to form short unconventional microtubules that have a unique function in the axonal transport. Sci. Rep. 7:16386. doi: 10.1038/s41598-017-15575-3

Tolia, A., and De Strooper, B. (2009). Structure and function of gamma-secretase. Semin. Cell Dev. Biol. 20, 211-218. doi: 10.1016/j.semcdb.2008.10.007

Toresson, H., and Grant, S. G. (2005). Dynamic distribution of endoplasmic reticulum in hippocampal neuron dendritic spines. Eur. J. Neurosci. 22, 17931798. doi: 10.1111/j.1460-9568.2005.04342.x

Tu, H., Nelson, O., Bezprozvanny, A., Wang, Z., Lee, S. F., Hao, Y. H., et al. (2006). Presenilins form ER Ca2+ leak channels, a function disrupted by familial Alzheimer's disease-linked mutations. Cell 126, 981-993. doi: 10.1016/j.cell. 2006.06.059

Tuttle, M. D., Comellas, G., Nieuwkoop, A. J., Covell, D. J., Berthold, D. A., Kloepper, K. D., et al. (2016). Solid-state NMR structure of a pathogenic fibril of full-length human alpha-synuclein. Nat. Struct. Mol. Biol. 23, 409-415. doi: 10.1038/nsmb.3194

Uhlen, M., Fagerberg, L., Hallstrom, B. M., Lindskog, C., Oksvold, P., Mardinoglu, A., et al. (2015). Proteomics. Tissue-based map of the human proteome. Science 347:1260419. doi: 10.1126/science.1260419

Utton, M. A., Noble, W. J., Hill, J. E., Anderton, B. H., and Hanger, D. P. (2005). Molecular motors implicated in the axonal transport of tau and alphasynuclein. J. Cell Sci. 118, 4645-4654. doi: 10.1242/jcs.02558

Vaikath, N. N., Majbour, N. K., Paleologou, K. E., Ardah, M. T., van Dam, E., van de Berg, W. D., et al. (2015). Generation and characterization of novel conformation-specific monoclonal antibodies for alpha-synuclein pathology. Neurobiol. Dis. 79, 81-99. doi: 10.1016/j.nbd.2015.04.009

Valente, E. M., Salvi, S., Ialongo, T., Marongiu, R., Elia, A. E., Caputo, V., et al. (2004). PINK1 mutations are associated with sporadic early-onset parkinsonism. Ann. Neurol. 56, 336-341. doi: 10.1002/ana.20256

Vital, A., Meissner, W. G., Canron, M. H., Martin-Negrier, M. L., Bezard, E., Tison, F., et al. (2014). Intra-axonal protein aggregation in the peripheral nervous system. J Peripher. Nerv. Syst. 19, 44-49. doi: 10.1111/jns5.12056
Volpicelli-Daley, L. A., Gamble, K. L., Schultheiss, C. E., Riddle, D. M., West, A. B., and Lee, V. M. (2014). Formation of alpha-synuclein Lewy neurite-like aggregates in axons impedes the transport of distinct endosomes. Mol. Biol. Cell 25, 4010-4023. doi: 10.1091/mbc.E14-02-0741

Wang, Q. C., Zheng, Q., Tan, H., Zhang, B., Li, X., Yang, Y., et al. (2016). TMCO1 is an $\mathrm{ER} \mathrm{Ca}(2+)$ load-activated $\mathrm{Ca}(2+)$ channel. Cell 165, 1454-1466. doi: 10.1016/j.cell.2016.04.051

Wilson, C. J., and Callaway, J. C. (2000). Coupled oscillator model of the dopaminergic neuron of the substantia nigra. J. Neurophysiol. 83, 3084-3100. doi: 10.1152/jn.2000.83.5.3084

Wuytack, F., Raeymaekers, L., and Missiaen, L. (2002). Molecular physiology of the SERCA and SPCA pumps. Cell Calcium 32, 279-305. doi: 10.1016/ S0143416002001847

Zahavi, E. E., Maimon, R., and Perlson, E. (2017). Spatial-specific functions in retrograde neuronal signalling. Traffic 18, 415-424. doi: 10.1111/tra.12487

Zeng, X. S., Geng, W. S., Jia, J. J., Chen, L., and Zhang, P. P. (2018). Cellular and molecular basis of neurodegeneration in Parkinson disease. Front. Aging Neurosci. 10:109. doi: 10.3389/fnagi.2018.00109

Zhang, S. J., Steijaert, M. N., Lau, D., Schutz, G., Delucinge-Vivier, C., Descombes, P., et al. (2007). Decoding NMDA receptor signaling: identification of genomic programs specifying neuronal survival and death. Neuron 53, 549-562. doi: 10.1016/j.neuron.2007.01.025

Conflict of Interest Statement: The authors declare that the research was conducted in the absence of any commercial or financial relationships that could be construed as a potential conflict of interest.

Copyright (c) 2018 Betzer and Jensen. This is an open-access article distributed under the terms of the Creative Commons Attribution License (CC BY). The use, distribution or reproduction in other forums is permitted, provided the original author(s) and the copyright owner(s) are credited and that the original publication in this journal is cited, in accordance with accepted academic practice. No use, distribution or reproduction is permitted which does not comply with these terms. 